notes among the Elias Ashmole collection now at the Bodleian Library, Oxford, which have greatly increased our knowledge of medical treatment, astrology, and the social mores of the day. ${ }^{7}$ It is easier, however, to recognise papers as "historical" if they are over 100 years old. Hospital administrators and medical records officers have to run an efficient service and justify costs for the present, not some 100 years in the future. And archivists are caught in a similar difficulty, most being unable to house records of such bulk while recognising that they will have an unknown (but clearly comparatively limited) use by historians. Moreover, they pose administrative difficulties arising from their normal closure period of 100 years unless the permission of the relevant authority is given (to protect confidentiality). Indeed, the issue of confidentiality compounds the problems, and, for different reasons, confuses the debate on the preservation of clinical and case records. ${ }^{89}$

The fundamental question of use therefore needs to be asked, if not resolved. Dr Charles Newman has set out some of the potential uses of clinical case notes, suggesting that they should be kept for historical rather than scientific research. " "The real reason," he wrote, "why case-notes are such an important source is because the first records are made in notes of patients under actual investigation. The material for original papers, monographs and books is often collected from case-notes. So that not only are case-notes the earliest record; they are also the most complete. They contain, even, the details which never come to publication. In other words, they tell you what was really done to patients, and from this is to be derived the most trustworthy and complete assessment of what doctors believed and thought at any given time, and how their minds were working."

But it is impossible to predict all the ways that archives will be used in the future, and with so many records and problems all the interested parties must get together and advise those who are being forced to take the decisions about what to do with the records under their supervision. This is the aim of a symposium which is being organised by the Wellcome Institute for the History of Medicine and the King's Fund Centre, which will take place in May 1985.

Five choices have so far been identified. Firstly, hospital clinical records might be kept in their original format (in which case we have to ask where, and who would pay). Secondly, they might be sampled or selected (in which case how, and where should the sample or selection be kept?). Thirdly, they might be microfilmed (cost must be remembered). Or they might be destroyed when they are no longer needed for legal purposes or after some agreed period such as $\mathbf{3 0}$ years. Or, finally, they might be kept, sampled, microfilmed, or destroyed according to local initiative-at random. This is what happens at the moment.

The symposium will be limited to a few invited participants. Some readers of the $B M F$ may already have faced this problem and may think that there are strong reasons for keeping or destroying some or all of these records. Any suggestions on how the problem of hospital clinical records can best be tackled, or comments on the options that have been identified, would be welcome so that these can be discussed at the symposium. Informed debate is essential before decisions.

AlEXANDRA NiCOL Liaison officer

Public Record Office,

Kew, Richmond, Surrey TW9 4DU

JULIA SHEPPARD Archivist

Wellcome Institute for the History of Medicine, London NW1 2BP
1 Public Records Act 1958. Section 1.

2 National Health Service. Preservation and destruction of hospital records. HM(61)73.

Department of Health and Social Security; Health Services Management. Retention of personal health records (for possible use in litigation). HM(80)7.

4 Davidson N. A Cook's tour of records. Health and Social Services Joumal 1979;89:690-1.

5 Report of Committee appointed by Lord Chancellor. Modern public records: selection and access. London: HMSO, 1981. (Cmnd 8204.)

6 Lord Chancellor's Department. Modem public records. London: HMSO, 1982. (Cmnd 8531.)

7 Macdonald M. Mystical bedlam. Cambridge: CUP, 1981.

8 Lock S. A question of confidence. An editor's view. Br Med J 1984;288: 123-5.

9 Loudon I. A question of confidence. How it strikes a historian. Br Med $\mathcal{J} 1984$;288:125-6.

10 Newman C. Medical records. Archives 1959;4:1-8.

\section{Road safety report: brickbats and bouquets}

Despite the introduction of compulsory wearing of front seat belts road accidents still constitute a huge public health problem. Every day on our roads 19 people are killed and a thousand are injured, and the Department of Transport has estimated that the total cost to the country in 1982 including a notional sum for pain, grief, and suffering was $£ 2370 \mathrm{~m}$. As the Royal Society for the Prevention of Accidents has said, if all the accidents in a single day occurred in the same place then both government and the public would demand that something dramatic should be done to reduce the carnage.

The first report from the House of Commons Transport Committee on Road Safety is thus to be welcomed for bringing the problem back to public attention. ${ }^{1}$ We also welcome the committee's suggestion that the government should recognise its failure to coordinate the work of the many departments that have something to do with road safety and set up a standing royal commission on road safety. We are not, however, sanguine that this will happen because Mrs Thatcher has still to set up her first royal commission after almost six years in office.

The report contains many other excellent suggestions, but there are a few deficiencies. Most of the media attention has been focused on the proposal to experiment with raising speed limits on motorways to $80 \mathrm{mph}$. Compared with other measures that might have an effect on road safety (either good or bad) speed limits are probably not that important, but they have a great symbolic value. The red blooded libertarian sees it as his inalienable right to drive his sports car as fast as he wants, whereas the doctors and others who have to pick up the pieces cannot see that getting from London to Birmingham five minutes faster is worth even a sprained wrist. So it is disappointing that the committee should have suggested this experiment in raising speed limits: even its own arguments seem to lead to keeping them unchanged. It accepts that higher speeds means more and worse accidents, but it muddles the statement by saying that the "relationship cannot be determined precisely." But hard evidence is available that higher speeds mean more deaths and accidents. ${ }^{2-5}$ Energy dissipated and stopping distance increase with the square of the speed; both are doubled when the speed rises from 60 to $82 \mathrm{mph}$.

Speed limits were reduced twice in Britain during the fuel crises of 1973-5, and both times there were reductions in deaths and accidents which could not be explained away by reduced traffic or other factors. ${ }^{45}$ All the decreases that have occurred in speed limits in Britain, the United States, France, and West Germany have led to reductions in accidents, and the lifting of all speed limits on German motorways in 1974 was followed by an $18 \%$ increase in deaths. ${ }^{2}$

What is more, the committee provides evidence that many motorists do not want the speed limit raised. The Auto- 
mobile Association said that it was in favour of raising speed limits and was sufficiently taken aback by the many letters of complaint that it received from its members to do some market research: this showed that of 1000 members $77 \%$ were in favour of keeping the limit.

The main argument for raising the speed limit seems to be the unimpressive one from the police that it is hard to enforce. But the National Speed Survey of 1983 showed that only $15 \%$ of motorway drivers were going at over $79 \mathrm{mph}$ and $60 \%$ were going at under 70 . Elsewhere in its report the committee deplores the estimate that only one in 7600 motoring offences is detected by the police and calls for more resources to be devoted to increasing the rate of detection. Surely rather than blithely suggest an experiment that we know will be dangerous and that most motorists do not want the committee should have called for more effective enforcing of the present limit. Modern technology could make this easy.

A second, and ultimately more important, failure of the committee was that it was too timid over the matter of testing drivers for alcohol. The Secretary of State told that committee that "to give the police the power to administer the breath test without a reasonable suspicion that the driver had been drinking or that an offence had been committed would be 'intolerable.' " The committee seems to have given in at this stage. We believe it should have followed both the Blennerhassett committee ${ }^{6}$ and the Central Policy Review Staff and recommended extending police powers. It is the chance of being caught that deters drivers, and, as the BMA said in its evidence to the committee, "the risk of a driver's apprehension in Britain with a blood alcohol in excess of $\mathbf{8 0}$ $\mathrm{mg} / 100 \mathrm{ml}$ is very small and this fact is increasingly recognised by the public."

A final failure of the committee was its unwillingness to make a recommendation on forcing the pace in the introduction of cycle lanes. This, we believe, is the single measure that could most reduce the number of cycling accidents. ${ }^{8}$ The recommendations for more education, examination of the benefits of helmets, and enforcing the minimum standards for lighting are all worth while, but they are not enough.

This particular failure probably reflects the make up of the committee; indeed, the whole tenor of its report is that motor vehicles come first. It is a transport committee, not just a roads committee, and it might (but did not) have taken the view that one of the best ways to reduce road accidents would be to get people out of cars and on to bikes and public transport, particularly trains, and to get goods out of lorries and into trains and possibly barges. Of course, at the moment if a driver gets out of his car and on to a bike he greatly increases his chances of being injured. But if most of the able bodied population were to desert their cars and if bicycles and cars were kept apart then injury rates, particularly for serious injuries, would surely fall.

Nevertheless, much of the report is welcome. It is quite right to call for all new cars to be fitted with rear seat belts because this simple measure will reduce deaths considerably, ${ }^{9}$ and also for more low cost engineering and traffic management schemes to help at accident black spots. There is also good reason for more examination of the benefits of head restraints and the case for fitting all new cars with laminated windscreens, ${ }^{10}$ although both of these recommendations could have been much stronger. Finally, the recommendations on more research into the relations between drugs and road accidents and putting warnings on drugs that are known to impair driving ability are eminently sensible.

1 House of Commons Transport Committee. Road safery. Vol 1. Report and minutes of proceedings. London: HMSO, 1984.

2 Breen JM, Newby RF. The implications for road safety of increasing the motorway speed limit for cars to $80 \mathrm{mph}$. London: Parliamentary Advisary Council for Transport Safety, 1984.

3 Anonymous. Accidents-speed and the roed environment. Br Med f 1978;ii: 1619-21.

4 Scott PP, Barton AJ. The effects on road accident rates of the fuel shorrage of November 1973 and subsequent legislation. Transport and Road Research Laboratory supplementary report 236. Crowthorne: TRRL, 1976.

5 Anonymous. Speed limits and the public health [Editorial]. Br Med f 1977; : $1045-6$.

6 Department of the Environment. Drinking and driving. London: HMSO, 1976. (Blennerhassett report.)

Bruun K. Alcohol policies in the United Kingdom. Stockholm: University of Stockholm, 1982.

Anonymous. Give cyclists room to move. Br Med $\mathcal{F}$ 1982;285:86.

Avery JG. Seat belt success: where next? Br Med J 1984;288:662-3.

10 Blake J. Road blindness. Br Med J 1983;287:626-7.

\section{Wool, eyes, and the limited list}

Next week is the deadline set by the DHSS for "consultation" on its limited list of drugs. The BMA has strongly opposed a list imposed by regulation (p 332). The BMF, too, has attacked the proposal from the outset ${ }^{1}$ and has been disappointed at the support given by some doctors, newspapers, and other commentators.

For the government has pulled a lot of wool over most people's eyes by claiming, firstly, that its proposals represent a move to generic prescribing and, secondly, that patients will not suffer. In Mr Fowler's words to Conservative MPs on 11 December-“doctors will still be free to prescribe any medicine if they and their patients wish."

The reality is that only for three benzodiazepine drugs has the DHSS imposed generic prescribing. Indeed, it has continued to refuse to consider saving money by introducing widescale generic substitution (as the BMA has urged), which would make no difference at all to doctors and patients but would cut the profits of the pharmaceutical industry. Instead Mr Clarke has chosen to remove from the NHS hundreds of symptomatic remedies for which there are no generic equivalents and scores of analgesics, hypnotics, and tranquillisers for which generic equivalents are available. From 1 April whether prescribed by generic name or by trade name these drugs will be available only to patients prepared to pay for them. Some practical implications have been spelt out in detail by the British Society of Gastroenterology (see p 327).

In the poorer parts of Britain more than three quarters of the prescriptions written by general practitioners are for patients exempt from prescription charges. These are the people who will pay from their own pockets much of the $£ 100$ million the government hopes to save.

1 Anonymous. Doctors, drugs, and the DHSS [Editorial]. Br Med f 1984;289:1397-8. 